\title{
CONCEPTUAL STUDY ON THE STATOR BLADES OF THE AXIAL FLOW COMPRESSOR WITH 'M' CUT
}

\author{
P.Sivakumar \\ Department of Aeronautical Engineering \\ Sri Ramakrishna Engineering College \\ Coimbatore, Tamil Nadu, India
}

\author{
P.Preethi Sivakami \\ Department of Aeronautical Engineering \\ Sri Ramakrishna Engineering College \\ Coimbatore, Tamil Nadu, India
}

\begin{abstract}
Axial flow compressor plays a major role in gas turbine and jet engines, ship powerplants, power stations and many industrial applications. The axial flow compressor consists of stages which comprises of a stationary part called stator and rotational part called rotor. In this study certain design changes in the stator blades has been considered and the influence of design changes in compressor performance such as the pressure ratio (ratio of the total air pressure exiting the compressor to the air pressure entering into the compressor) are been analyzed. NACA 65410 profile with the aspec ratio of 0.5 is considered for stator blade. The blade is designed in CATIA V5. Two ' $M$ ' cuts are created at the trailing edge of the stator blades. CFD analysis has been carried out using ANSYS CFX tool to analyze the flow over the stator blades. Continuous vortices are induced in the trailing edge region due to the presence of ' $M$ ' cuts on the stator blades. Vortices patterns for each stator and their influence are compared.
\end{abstract}

Key Words - Stator with 'M' cut, Vorticity, Pressure ratio

\section{INTRODUCTION}

In turbomachinery a blade or row of blades rotates and imparts or extracts energy to or from the fluid. Work is generated or extracted by means of enthalpy changes in the working fluid. Turbomachines may be further classified into two categories: those that absorb energy to increase the fluid pressure, i.e. Pumps, Compressors, and Fans, and those that produce energy such as turbines by expanding to lower pressures. A compressor is a device which increases the pressure of gas by reducing its volume. Axial-flow compressors are dynamic rotating compressors that use arrays of fan-like aero foils to progressively compress a fluid. Number of airfoils is set in rows, usually as pairs: one will rotates and other remains stationary. The rotating airfoils accelerates the fluid, are known as blades or rotors. The
Airfoils which is stationary, also known as stators or vanes, decelerate and redirect the flow direction of the fluid, preparing it for the rotor blades of the next stage. Axial compressors are typically multi-staged.

The traditional approach to axial-flow compressor aerodynamic design was to use various families of aero foils as the basis for blade design. NACA 65410 Aero foil is considered for the design of stator blades

\section{ANALYSIS OF DESIGN USING CFD TOOLS}

Analysis of design involves following steps.

1. Geometry

2. Physics of the Model

3. Solving the CFD Problem

\section{Geometry}

The stator blades are designed in CATIA V5. A cascade of three stator blades is assembled in a rectangular plate. The chord of the stator blade is $200 \mathrm{~mm}$ and the length of the blade is $100 \mathrm{~mm}$. The aspect ratio (ratio between length of blade to chord length) of the stator blade is 0.5 .

The ' $M$ ' cuts are made in the trailing edge of the stator blade. Two types of stator blades are designed based on the position of the ' $M$ ' cuts. In design 1 the ' $M$ ' cuts are made in the sides of the trailing edge. In design 2 one ' $M$ ' cut is made in the centre of the trailing edge and the other ' $M$ ' cut is made in the side of the training edge in the stator blade.

The two ' $M$ ' cuts considered in the design 1 are made in the trailing edge of the stator blades with dimensions 10 $\mathrm{mm}$ and $80 \mathrm{~mm}$ from the reference axis. In design 2 the ' $\mathrm{M}$ ' cuts are made in the trailing edge of the stator blades with dimensions $40 \mathrm{~mm}$ and $80 \mathrm{~mm}$ from the reference axis. A cascade of three blades are made with one end fixed for the analysis.

\footnotetext{
Table -1 Dimensions of ' $M$ ' cut
} 
International Journal of Engineering Applied Sciences and Technology, 2019

Vol. 3, Issue 12, ISSN No. 2455-2143, Pages 81-84

Published Online April 2019 in IJEAST (http://www.ijeast.com)

\begin{tabular}{|l|l|}
\hline Base length & $10 \mathrm{~mm}$ \\
\hline Height & $10 \mathrm{~mm}$ \\
\hline Angle & $60^{\circ}$ \\
\hline Cut phase line & $5 \mathrm{~mm}$ \\
\hline
\end{tabular}

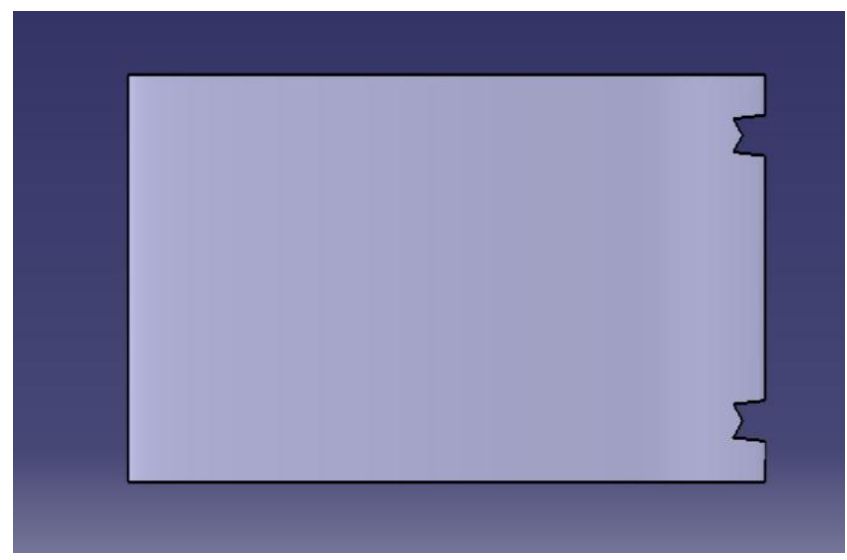

Fig. 1. Stator blade with 'M' cut at tip

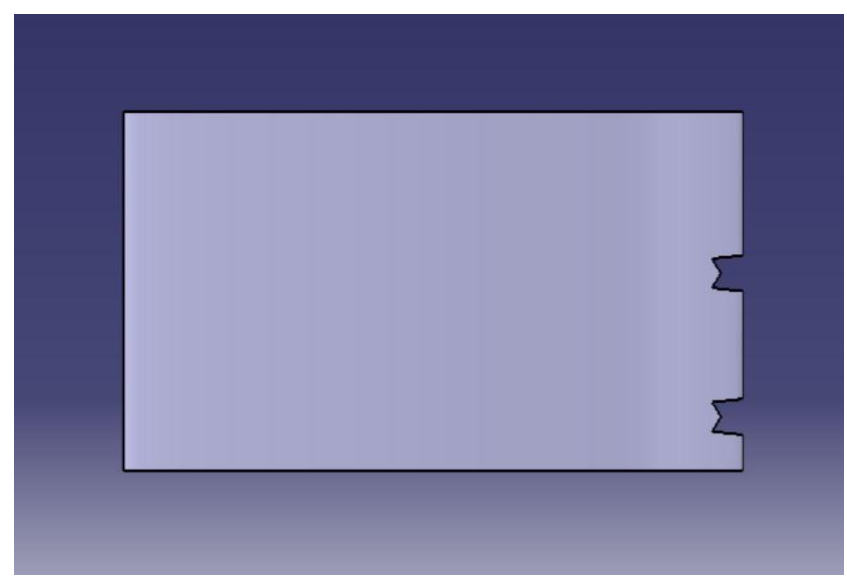

Fig. 2. Stator blade with 'M' cut at tip and mid span

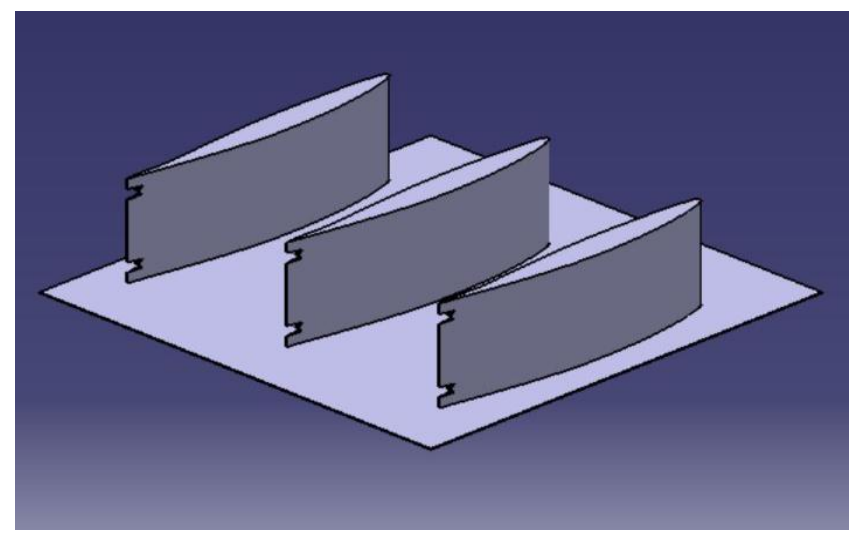

Fig. 3. Cascade view stator blades with ' $M$ ' cuts at tip

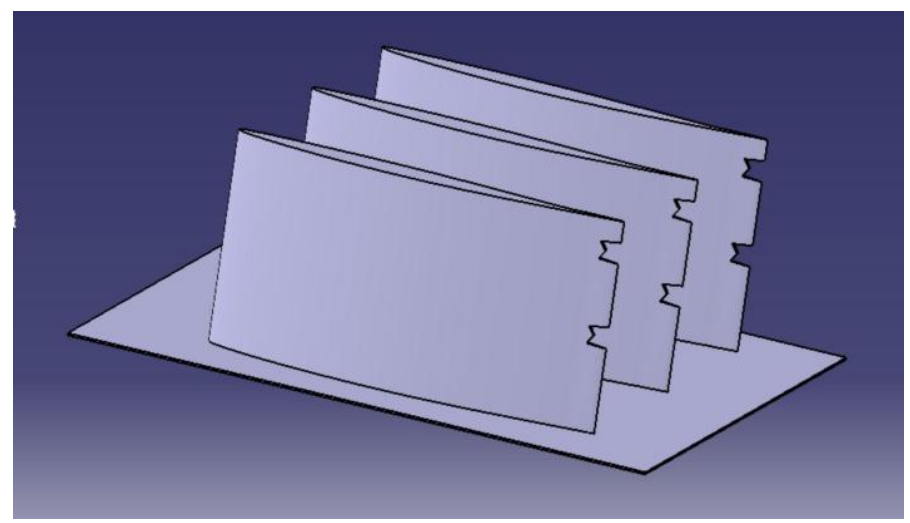

Fig. 4. Cascade view stator blades with ' $\mathrm{M}$ ' cuts at tip and midspan

\section{Physics of the Model}

The specifications of the analysis domain is with 5287463 number of hexagonal elements.

\begin{tabular}{|l|l|}
\multicolumn{2}{|c|}{ Table -2 Boundary Conditions } \\
\hline Type of flow & Subsonic flow \\
\hline Mach number & 0.5 \\
\hline Total pressure & $20 \mathrm{bar}$ \\
\hline Normal speed & $170 \mathrm{~m} / \mathrm{s}$ \\
\hline Mass flow rate & $20 \mathrm{~kg} / \mathrm{s}$ \\
\hline Flow direction & Normal to boundary \\
\hline Turbulence medium of intensity & $5 \%$ \\
\hline Static pressure & $1 \mathrm{bar}$ \\
\hline Mass flow rate & $20 \mathrm{~kg} / \mathrm{s}$ \\
\hline
\end{tabular}

\section{Solving the CFD Problem}

CFX Pre-Solver parameters are set as under.

1. Air at $298 \mathrm{~K}$ is taken as working fluid.

2. The solid domain motion is taken as stationary.

Using ANSYS CFX-Solver Manager for Solution of problem associated with the physical variables such as velocity, pressure and mass flow rate are monitored.

\section{RESULTS}

The pressure and velocity distribution across the stator blades without ' $M$ ' cut, ' $M$ ' cuts in the sides of the stator blade (Design 1) and ' $M$ ' cuts in the center and sides of the stator blade (Design 2) are analyzed and studied.

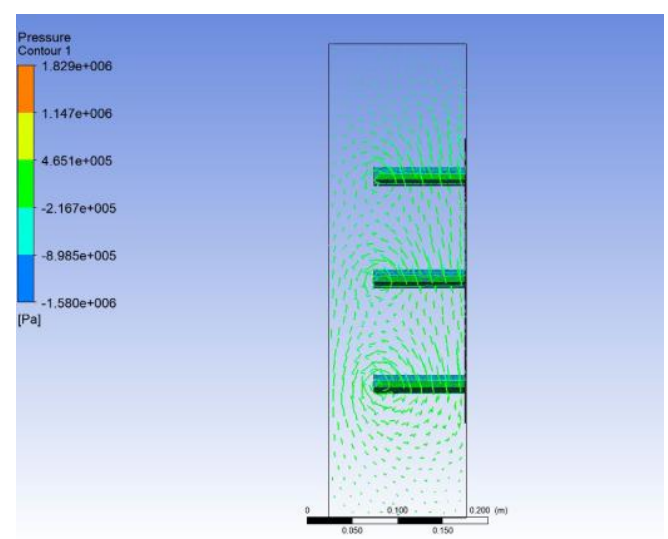




\section{International Journal of Engineering Applied Sciences and Technology, 2019 \\ Vol. 3, Issue 12, ISSN No. 2455-2143, Pages 81-84 \\ Published Online April 2019 in IJEAST (http://www.ijeast.com)}

Fig. 5. Contour Pressure for stator blades without cuts

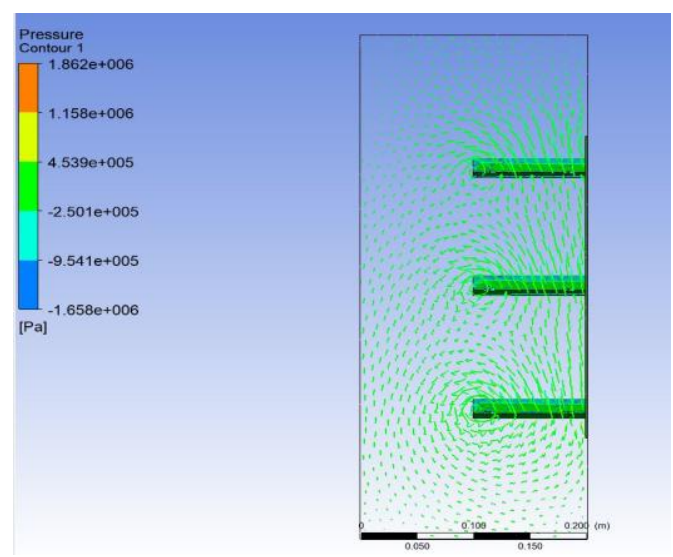

Fig. 6. Contour Pressure for M cuts at the tips

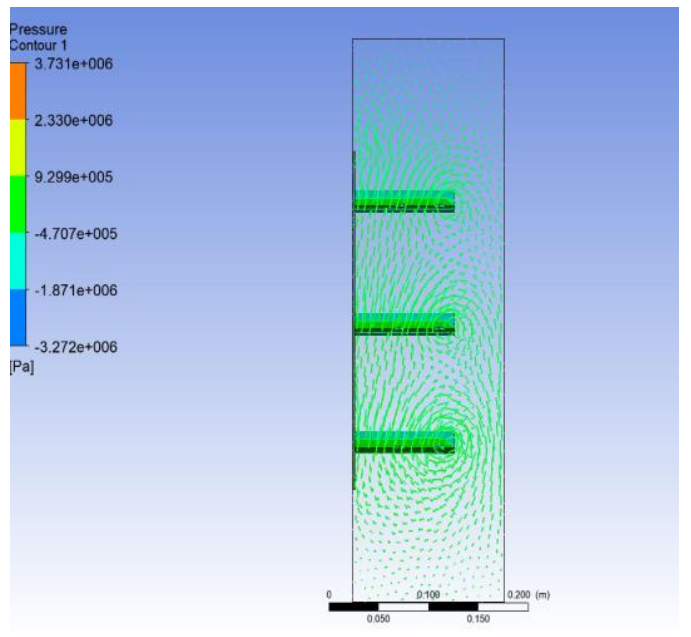

Fig. 7. Contour Pressure for M cuts in tip and midspan

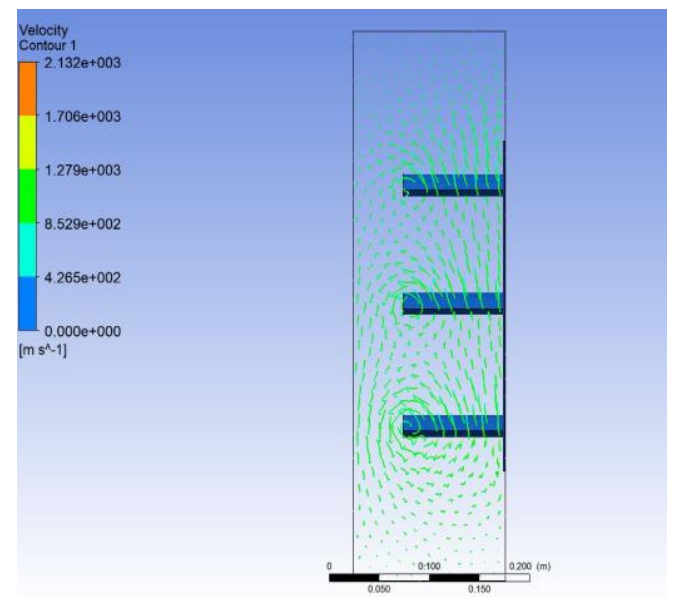

Fig. 8. Contour Velocity for stator blades without cuts

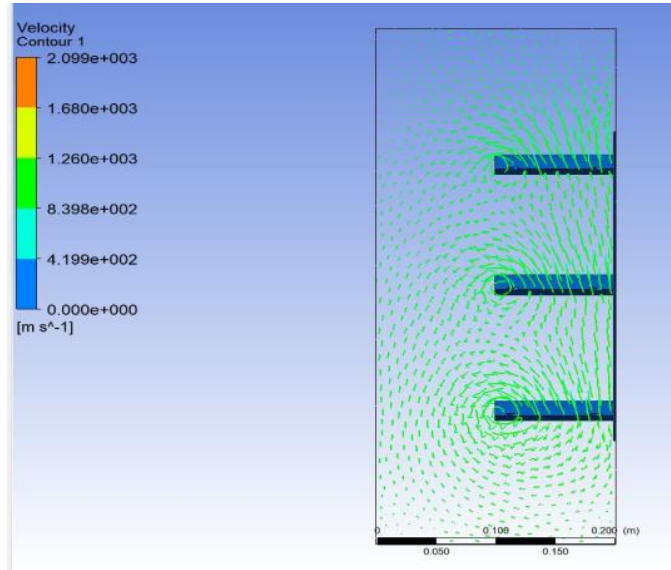

Fig. 9. Contour Velocity of $\mathrm{M}$ cuts at the tips

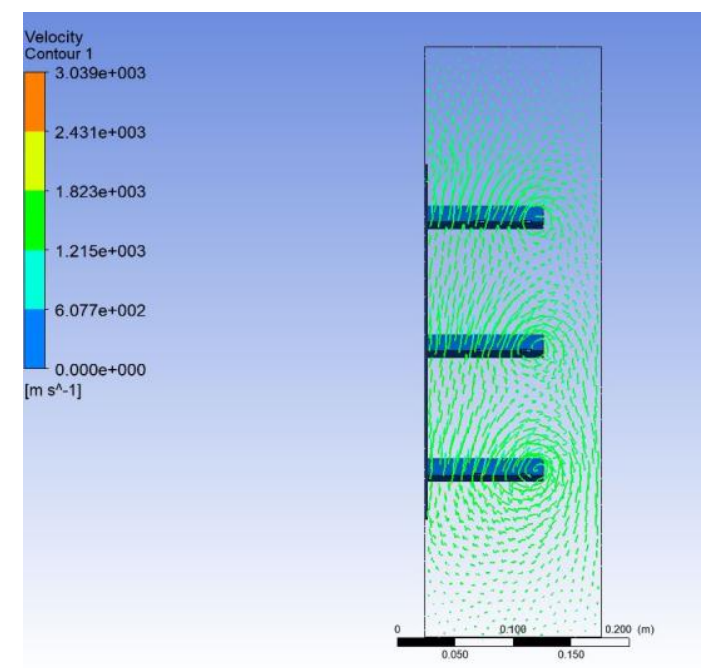

Fig. 10. Contour Velocity for M cuts at the tip and midspan

\section{FUTURE WORKS}

The analytical work can be continued with following considerations,

- The angle, dimensions and the number of ' $M$ ' cut can be varied and its influence in the performance of the axial flow compressor can be studied.

- The cuts can also be done in the rotor of the compressor.

- The design can be experimentally verified with the results.

- The distance between the blade orientation in the plate can be varied and its influence can be observed.

- This design can also be used in the stages of the centrifugal compressor and the compressor performance can be studied. 


\section{CONCLUSION}

From the results of the analysis it can be observed that the vortices pattern formed in each stator blades varies with the change in position of the ' $\mathrm{M}$ ' cuts in the trailing edge of stator blade. The pressure is apparently increased by $6.2 \%$ in the stator blades with ' $\mathrm{M}$ ' cut when compared to the stator blades without ' $\mathrm{M}$ ' cut.

Continuous vortices are induced in the trailing edge region due to the presence of ' $M$ ' cuts on the stator blades which indicates the pressure change because of vortex effect. Vorticity patterns for each stator are studied and their influence in the performance of the compressor is interpreted.

Thus it can be conclude that trailing edge ' $M$ ' cuts on the stator blades is majorly influencing on the pressure ratio of the stages thereby significantly changes the overall pressure ratio of the axial flow compressor.

\section{ACKNOWLEDGEMENT}

The authors thank the Department of Aeronautical Engineering of Sri Ramakrishna Engineering College for providing the facilities to complete the project successfully.

\section{REFERENCES}

1. Dr. Shaker H. Aljanabi, Asmaa Ali Hussein, Karema Assi Hamad, Lamyaa hussan Hamzia. (2012). Design and Performance Prediction of an Axial Flow Compressor". Anbar Journal for Engineering Sciences.

2. Ujjawal A. Jaiswal, Prof. S. J. Joshi. (2013). Design and Analysis of Stator, Rotor and Blades of Axial flow Compressor. IJEDR.

3. Karthick Raja. R, Maniarasan. P. (2015). Numerical Investigation of Single Stage of an Axial Flow Compressor for Effects of Blade Aspect Ratio. IJERA,(Pg 99).

4. S J Gallimore. (1999). Axial flow compressor design. SAGE Journals.

5. S.L. Dixon, B.Eng., PH.D. Senior Fellow at the University of Liverpool. (1998). Fluid Mechanics, Thermodynamics of Turbo machinery, Fourth Edition. Pergamon Press.

6. Hill.P. and Peterson.C. (1992). Mechanics and Thermo dynamics of Propulsion, $2^{\text {nd }}$ Edition. Addison Wesley.

7. Airfoil Tools, http://airfoil tools.com/ airfoil/ details?airfoil= naca64a410-il

8. Ronald H. Aungier. (2003). Axial Flow Compressor. $2^{\text {nd }}$ Edition. ASME Press.

9. Logon, Earl, Jr. (1993).Turbomachinery Basic Theory and Applications. Marcel Dakker, Inc.

10. V Ganesan (2010). Gas Turbines. $3^{\text {rd }}$ Edition. Tata McGraw Hill, New Delhi.
11. Lesser A. (2012). Numerical Investigation of The Effect Of Inflow Distortions on Transonic Axial Compressor Stages With 2d and 3d Calculations', $28^{\text {th }}$ International Congress Of The Aeronautical Sciences.

12. Mdouki R. (2013). Effects of Slotted Blading On Secondary Flow In Highly Loaded Compressor Cascade', Journal of Engineering Science and Technology Vol. 8, No. 5, pg: 540-556. 